Hal 12-19

\title{
ANALISA MANFAAT INTERPROFESSIONAL EDUCATION PADA PENDIDIKAN DAN PRAKTIK KEPERAWATAN JIWA
}

\author{
Muhammad Agung Krisdianto ${ }^{1}$, Maula Mar'atus Solikhah ${ }^{2}$ \\ Universitas Kusuma Husada Surakarta \\ Surakarta, (0271) 857724 \\ Email: magungkrisdianto@gmail.com
}

\begin{abstract}
ABSTRAK
Latar Belakang: Upaya peningkatan kualitas pendidikan saat ini terus dilakukan dengan mulai menambahkan metode pembelajaran yang lebih aplikatif dan mampu memenuhi tuntutan stakeholder. World Health Organization (WHO) mencanangkan untuk mengatasi permasalahan sumber daya manusia kesehatan serta sistem pelayanan kesehatan dengan menerapkan praktik kolaborasi diantara tenaga kesehatan. Interprofessional Education (IPE) yang juga dikenal dengan istilah interprofessional learning, merupakan suatu konsep Pendidikan yang direkomendasikan oleh WHO sebagai pendidikan terintegrasi untuk membangun kolaborasi antara tenaga kesehatan. Tujuan: Menganalisa manfaat IPE pada pendidikan dan praktik keperawatan jiwa. Metode: Penelitian ini menggunakan metode literature review. PICO digunakan dalam memilih dan menentukan data artikel yang akan digunakan sebagai bahan kajian literature review. Data diolah menggunakan analisa konten.

Hasil: IPE bermanfaat untuk pendidikan dan praktik keperawatan jiwa berdasarkan kajian ilmiah yang telah dilakukan. Kesimpulan: IPE memiliki manfaat dalam pendidikan dan praktik keperawatan sehingga dapat mengatasi masalah-masalah yang timbul dalam ilmu keperawatan jiwa.
\end{abstract}

Kata Kunci: IPE, Keperawatan Jiwa

\section{ABSTRACT}

Background: Efforts to improve the quality of education are currently being made by starting to add learning methods that are more applicable and able to meet stakeholder demands. The World Health Organization (WHO) has launched a program to address human resource problems in health and the health service system by implementing collaborative practices among health workers. Interprofessional Education (IPE), also known as interprofessional learning, is an education concept recommended by WHO as integrated education to build collaboration between health workers. Objective: To analyze the benefits of IPE on mental health nursing education and practice. Methods: This study used a literature review method. PICO is used in selecting and determining article data to be used as material for a literature review. The data is processed using content analysis. Result: IPE is useful for mental health nursing education and practice based on scientific studies that have been conducted. Conclusion: IPE has benefits in nursing education and practice so that it can overcome problems that arise in mental health nursing.

Keywords: IPE, Mental Health Nursing 


\section{Latar Belakang}

Interprofessional Education (IPE) yang juga dikenal dengan istilah interprofessional learning, merupakan suatu konsep pendidikan yang direkomendasikan oleh World Health Organisation (WHO) sebagai Pendidikan terintegrasi untuk membangun kolaborasi antara tenaga kesehatan. Interprofessional education adalah proses dimana kita melatih atau mendidik praktisi untuk bekerja kolaboratif dan proses yang kompleks yang menuntut kita untuk melihat pembelajaran berbeda (CIHC, 2009). Pendidikan interprofessional ini mengacu pada kesempatan ketika anggota dari dua atau lebih profesi belajar dengan satu sama lain untuk meningkatkan kolaborasi dan kualitas pelayanan (CAIPE, 2002). Interprofessional Education (IPE) bertujuan menghasilkan tenaga kesehatan yang memiliki pengetahuan, keterampilan, dan sikap yang mendukung praktik kolaborasi antarprofesi kesehatan (Speakman, 2015).

$$
\text { Praktek kolaborasi dan }
$$

Interprofessional Education (IPE) merupakan dua hal yang diperlukan untuk mengatasi beberapa permasalahan pelayanan kesehatan di Indonesia. Atas dasar pentingnya pendidikan interprofesi bagi mahasiswa kesehatan, Interprofessional Education (IPE) saat ini bahkan menjadi kurikulum tingkat ASEAN dan menjadi unggulan pada setiap program studi yang melaksanakannya.

Di Indonesia, Interprofessional Education (IPE) saat ini sudah mulai dirancang oleh beberapa institusi-institusi pendidikan kesehatan di Indonesia untuk diintergrasikan dalam kurikulum pendidikan kesehatan. Selain itu, praktek kolaborasi juga telah mulai diinisiasi oleh beberapa institusi pelayanan kesehatan (A'la, 2012).

Pada cabang ilmu keperawatan jiwa masih sangat minim referensi yang dapat dijadikan rujukan dalam pengembangan manfaat IPE diranah pendidikan dan praktik. Oleh sebab itu peneliti tertarik untuk mengambil tema analisa manfaat IPE pada pendidikan dan praktik keperawatan jiwa.

\section{Metode}

Penelitian yang dilakukan adalah jenis literature review. Data dalam penelitian ini adalah artikel jurnal yang didapatkan dari mesin pencari google scholar. Teknik sampling yang digunakan adalah purposive sampling (sesuai tujuan), dengan penerapan screening PICO. Demi memperkuat argumen data maka dilakukan proses inklusi dan ekslusi untuk pencarian artikel jurnal. 


\section{Hasil}

Berdasarkan hasil analisa PICO dan penerapan kriteria inklusi dan ekslusi dalam pencarian data, maka didapatkan 5 artikel jurnal. Hasil jurnal disajikan dalam bentuk tabel yang kemudian akan dianalisa. Analisa yang digunakan adalah analisa konten, sehingga inti dari data disajikan tanpa ada proses narasi.

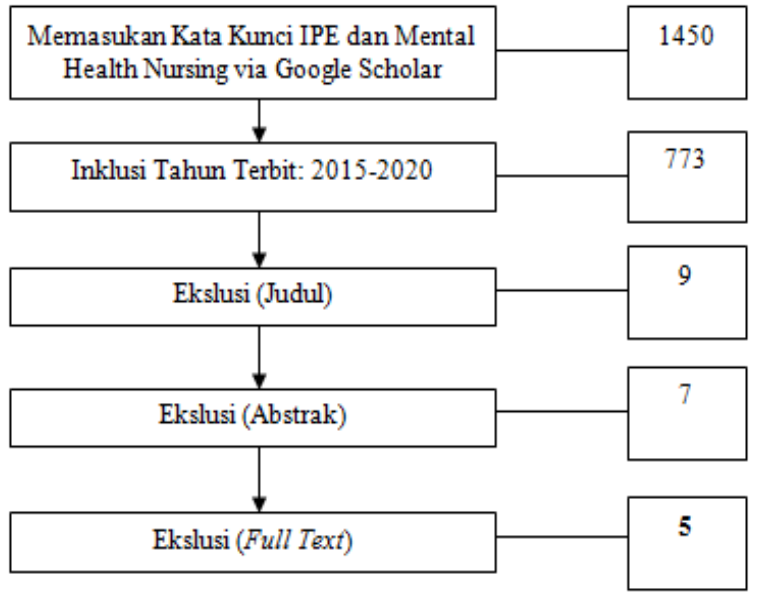

Gambar 1. Pencarian Artikel Ilmiah

Tabel 2. Hasil Artikel Jurnal

\begin{tabular}{|c|c|c|c|c|c|}
\hline No & $\begin{array}{l}\text { Penulis } \\
\text { (Tahun) }\end{array}$ & Judul & Metode & Hasil & Penerbit \\
\hline 1 & $\begin{array}{l}\text { Maranzan } \\
(2016)\end{array}$ & $\begin{array}{l}\text { Interprofessional education in } \\
\text { mental health: An opportunity to } \\
\text { reduce mental illness stigma }\end{array}$ & $\begin{array}{l}\text { Literature } \\
\text { Review }\end{array}$ & $\begin{array}{l}\text { IPEMenurunkan Stigma } \\
\text { di Masyarakat dan } \\
\text { Pembelajaran }\end{array}$ & $\begin{array}{c}\text { Joumal of } \\
\text { Interprofessional } \\
\text { Care }\end{array}$ \\
\hline 2 & $\begin{array}{l}\text { Munoz, etal } \\
(2020)\end{array}$ & $\begin{array}{l}\text { Interprofessional education in } \\
\text { nursing: The impact of } \\
\text { collaborationbetween physical and } \\
\text { mental health care professionals }\end{array}$ & Mix Method & $\begin{array}{l}\text { IPE meningkatkan sikap } \\
\text { caring }\end{array}$ & $\begin{array}{l}\text { Intemational Joumal } \\
\text { of Nursing Sciences }\end{array}$ \\
\hline 3 & $\begin{array}{l}\text { Mastel, et al } \\
\text { (2019) }\end{array}$ & $\begin{array}{l}\text { Dementia care boot camp: } \\
\text { interprofessionaleducation for } \\
\text { healthcare students }\end{array}$ & Mix Method & $\begin{array}{l}\text { IPE berpengaruh } \\
\text { terhadap peningkatan } \\
\text { sikap empati, } \\
\text { pengetahuan dan } \\
\text { kepercayaan diri }\end{array}$ & $\begin{array}{c}\text { Joumal of } \\
\text { Interprofessional } \\
\text { Care }\end{array}$ \\
\hline 4 & $\begin{array}{l}\text { Nelis, et al } \\
(2015)\end{array}$ & $\begin{array}{lrr}\text { Interprofessional Education in } \\
\text { Mental Health: } & \text { Developing } \\
\text { Practitioners to } & \text { Work } \\
\text { Collaboratively in } & \text { Providing } \\
\text { Patient-centered Care } & \\
\end{array}$ & Qualitative & $\begin{array}{l}\text { IPE meningkatkan } \\
\text { pemahaman } \\
\text { pembelajaran dankerja } \\
\text { sama antar disiplin ilmu }\end{array}$ & $\begin{array}{c}\text { Cambridge } \\
\text { University Press }\end{array}$ \\
\hline 5 & $\begin{array}{l}\text { Stewart, et al } \\
(2016)\end{array}$ & $\begin{array}{l}\text { Interprofessional learning issues in } \\
\text { post graduate mental health } \\
\text { education }\end{array}$ & Qualitative & $\begin{array}{l}\text { IPE meningkatkan } \\
\text { pemahaman tentang } \\
\text { praktik professional }\end{array}$ & $\begin{array}{l}\text { Joumal of Social } \\
\text { Inclusion }\end{array}$ \\
\hline
\end{tabular}


Data yang didapakan berupa 5 artikel jurnal yang membahas tentang manfaat IPE. Artikel ilmiah oleh Maranzan (2016) dan Mastel et al (2019) yang diterbitkan oleh Journal of Interprofessional Care. Artikel ilmiah oleh Munoz et al (2020) yang diterbitkan oleh International Journal of Nursing Sciences. Artikel ilmiah oleh Nelis et al (2015) diterbitkan oleh Cambridge University Press. Artikel ilmiah oleh Stewart et al (2016) yang diterbitkan oleh Journal of Social Inclusion.

\section{Pembahasan}

Interprofessional Education (IPE) memiliki manfaat dalam pendidikan dan praktik keperawatan jiwa (Carpenter dan Dickinson, 2016). Beberapa manfaat IPE dalam pendidikan dan praktik adalah:

1. Manfaat IPE dalam Pendidikan Keperawatan Jiwa

a. IPE Meningkatkan Pengetahuan Salah satu manfaat IPE dalam pendidikan keperawatan jiwa adalah meningkatkan pengetahuan tentang keperawatan jiwa (Mastel et al, 2019). Dengan melaksanakan IPE sesuai dengan prosedur maka seseorang akan dapat meningkatkan pengetahuan tentang apa yang ia pelajari (Monteiro et al, 2017; Cohen et al, 2016).
IPE adalah metode yang tepat dalam meningkatkan pengetahuan mahasiswa dalam proses belajar mengajar (Hinderer et al, 2016). Penelitian ini juga didukung oleh penelitian Weston et al (2018) yang menjelaskan bahwa IPE mampu meningkatkan pengetahuan seseorang. Data diatas menunjukan bahwa IPE dapat meningkatkan pengetahuan mahasiswa dalam proses belajar mengajar.

\section{b. IPE Meningkatkan Rasa Percaya Diri} Fungsi lain IPE adalah meningkatkan rasa percaya diri mahasiswa dalam melakukan proses pembelajaran keperawatan jiwa (Mastel et al, 2019). IPE memberikan kesempatan secara merata pada mahasiswa untuk mengemukakan pendapat. Dengan kesempatan yang diberikan pada proses IPE, mahasiswa dapat meningkatkan rasa percaya diri (Weston et al, 2018). Penerapan IPE adalah salah satu upaya dalam memberikan kesempatan kepada mahasiswa untuk meningkatkan rasa percaya diri dalam proses belajar mengajar (Mills et al, 2020).

Penlitian ini didukung oleh penelitian Hienderer (2016) yang menjelaskan bahwa IPE dapat meningkatkan rasa percaya diri mahasiswa. Dari data diatas diketahui bahwa IPE dapat meningkatkan rasa percaya diri pada mahasiswa. 
c. IPE Meningkatkan Pemahaman

Pembelajaran

IPE berfungsi sebagai metode yang dapat meningkatkan pemahaman mahasiswa dalam mempelajari materi tentang keperawatan jiwa (Nelis et al, 2015). Penerapan IPE terhadap mahasiswa dapat meningkatkan pemahaman mahasiswa terhadap materi yang dipelajari (Zanotti et al, 2015). Penelitian ini didukung oleh penelitian Homeyer et al (2018) yang menjelaskan bahwa IPE dapat meningkatkan pemahaman pembelajaran pada mahasiswa. Dari data diatas dapat disimpulkan bahwa IPE mampu meningkatkan pemahaman dalam pembelajaran.

d. IPE Meningkatkan Pemahaman Praktik Profesional

Penerapan IPE memberikan pengalaman yang nyata tentang bagaimana proses praktik profesional dilahan klinis maupun komunitas (Carpenter dan Dickinson, 2016). Penelitian ini didukung oleh penelitian Meleis et al, (2016) yang menjelaskan bahwa IPE mampu meningkatkan pemahaman praktik profesional pada masa pembelajaran. Dari data diatas menunjukan bahwa IPE mampu meningkatkan Pemahaman Praktik Profesional.
IPE mampu meningkatkan pemahaman terhadap praktik profesional dalam keperawatan jiwa (Steward et al, 2016). IPE memberikan gambaran dalam masa pembelajaran tentang praktik profesional (Thistlethwaite, 2016).

2. Manfaat IPE dalam Praktik Keperawatan Jiwa

a. Interprofessional Education (IPE) Mencegah Stigma

IPE mampu mencegah stigma dalam praktik keperawatan jiwa (Maranzan, 2016). Proses IPE memberikan gambaran kepada mahasiswa mulai dari bagaimana stigma terbentuk hingga terjadi dimasyarakat (Edwards, 2020).

IPE memberikan strategi kepada profesi kesehatan maupun non kesehatan untuk mengatasi pembentukan stigma (Maranzan, 2016). Penelitian ini didukung oleh penelitian Edwards (2016) yang menjelaskan bahwa IPE mampu mencegah stigma dimasyarakat. Dari data diatas dapat disimpulkan bahwa IPE mampu mencegah stigma.

\section{b. IPE Meningkatkan Sikap Caring}

IPE bermanfaat dalam meningkatkan sikap caring terhadap perawat dalam praktik keperawatan jiwa (Munoz et al, 2019). 
Sikap caring muncul setelah perawat mampu memahami kondisi pasien dalam sudut pandang secara menyeluruh (Mahoney et al, 2017). Manfaat IPE dalam membentuk sifat caring dalam praktik keperawatan jiwa dimulai dari pemahaman kasus hingga implementasi tindakan secara langsung ke pasien (Olander et al, 2018). Penelitian ini didukung oleh penelitian Mahoney et al (2017) yang menjelaskan bahwa IPE mampu meningkatkan sikap caring. Dari data diatas dapat disimpulkan bahwa IPE mampu meningkatkan sikap caring.

\section{c. IPE Meningkatkan Sikap Empati}

Manfaat lain dari IPE adalah meningkatkan sikap empati terhadap pasien dalam praktik keperawatan jiwa (Mastel et al, 2019). Sikap empati dihasilkan oleh proses IPE dalam membahas kehidupan dan latar belakang pasien dalam perawatannya (Lindqvist \& Reeves, 2007). Pembentukan sifat empati dalam keperawatan jiwa menekankan proses pendekatan dan pendalaman yang dilakukan terhadap pasien (Mastel et al, 2019). Penelitian ini didukung oleh penelitian Lindqvist \& Reeves (2007) yang menjelaskan bahwa IPE mampu meningkatkan sikap empati perawat. Dari data diatas dapat disimpulkan bahwa IPE mampu meningkatkan sikap empati perawat. d. IPE Meningkatkan Kerjasama Antar Disiplin Ilmu

Manfaat IPE lainnya adalah meningkatkan kerjasama antar displin ilmu khususnya dalam praktik keperawatan jiwa (Nelis et al, 2015).

Manfaat IPE ini tidak lepas dalam proses yang melibatkan lebih dari 3 profesi (Alasane \& Slattum, 2016). Salah satu tujuan IPE adalah mengetahui bagaimana mencari jalan keluar untuk memecahkan suatu masalah dengan melibatkan lebih dari satu disiplin ilmu (Carpenter \& Dickinson, 2016). Penelitian ini didukung oleh penelitian Wong et al (2016) yang menjelaskan bahwa IPE mampu meningkatkan kerjasama antar disiplin ilmu.

\section{Kesimpulan}

Dalam 5 tahun terakhir hanya didapatkan 5 artikel jurnal ilmiah yang membahas tentang manfaat Interprofessional Education (IPE) dalam pendidikan dan praktik keperawatan jiwa. Manfaat IPE dalam keperawatan jiwa dibagi menjadi dua yaitu pendidikan daan praktik. Manfaat IPE dalam pendidikan adalah meningkatkan pengetahuan, meningktakan rasa percaya diri, meningkatkan pemahaman pembelajaran dan meningkatkan pemahaman tentang praktik profesional. Dalam praktik adalah mencegah stigma, meningatkan sikap caring, meningkatkan sikap empati dan meningkatkan kerjasama antar disiplin ilmu. 


\section{Ucapan Terima Kasih}

Peneliti mengucapkan terima kasih kepada Rektor dan Ketua Lembaga Penelitian dan Pengabdian Kepada Masyarakat Universitas Kusuma Husada Surakarta yang telah memberi dukungan moril dan materil dalam menyelesaikan publikasi ini.

\section{Daftar Pustaka}

A'la, M. Z. (2012). Interprofessional

Education (IPE) dan Peningkatan Mutu Pelayanan Kesehatan.

Canadian Interprofessional Health Collaborative. (2010) A National Interprofessional Competency Framework. http://www.cihc.ca/files/CIHC_IPComp etencies_Feb1210.pdf

Carpenter, J., \& Dickinson, H. (2016). Interprofessional education and training $2 e$. policy press.

Centre for the Advancement of Interprofessional Education (CAIPE). (2002). Defining IPE. http://www.caipe.org.uk/about--us/defining---ipe/Centre for the Advancement of Interprofessional Education (CAIPE). Interprofessional Education. 1997.

Cohen, E. V., Hagestuen, R., GonzálezRamos, G., Cohen, H. W., Bassich, C., Book, E., ... \& Giroux, M. (2016). Interprofessional education increases knowledge, promotes team building, and changes practice in the care of Parkinson's disease. Parkinsonism \& Related Disorders, 22, 21-27.

Edwards, S., Ferguson, T. F., Gunaldo, T. P., \& Molina, P. E. (2020, June). Evidence That Interprofessional Education (IPE) Reduce Stigma and
Improves Confidence in Future Team Based Treatment of Alcohol Use Disorder. In Alcoholism-Clinical and Experimental Research (Vol. 44, pp. 182-182). 111 River ST, Hoboken 07030-5774, NJ USA: Wiley.Speakman, E., Shoshana Sicks, Collins, L.,

Hinderer, K. A., Klima, D., Truong, H. A., Rangel, A. G., Brown, V., Talley, W., ... \& Joyner Jr, R. L. (2016). Faculty perceptions, knowledge, and attitudes toward interprofessional education and practice. Journal of Allied Health, 45(1), 1E-4E.

Homeyer, S., Hoffmann, W., Hingst, P.,

Oppermann, R. F., \& DreierWolfgramm, A. (2018). Effects of interprofessional education for medical and nursing students: enablers, barriers and expectations for optimizing future interprofessional collaboration-a qualitative study. BMC nursing, 17(1), 13.

Lindqvist, S. M., \& Reeves, S. (2007).

Facilitators' perceptions of delivering interprofessional education: a qualitative study. Medical Teacher, 29(4), 403-405.

Mahoney, J. S., Mulder, C., Hardesty, S., \& Madan, A. (2017). Integrating caring into patient-centered care through interprofessional education and ethics: The Caring Project. Bulletin of the Menninger Clinic, 81(3), 233-246.

Maranzan, K. A. (2016). Interprofessional education in mental health: An opportunity to reduce mental illness stigma. Journal of interprofessional care, 30(3), 370-377.

Mastel-Smith, B., Kimzey, M., Garner, J., Shoair, O. A., Stocks, E., \& Wallace, T. (2019). Dementia care boot camp: interprofessional education for healthcare students. Journal of Interprofessional Care, 1-13. 
McNelis, A., Horton-Deutsch, S., \& Lay, K. (2015). Interprofessional education in mental health: Developing practitioners to work collaboratively in providing patient-centered care. European Psychiatry, 30(S1), 1-1.

Meleis, A. I. (2016). Interprofessional education: A summary of reports and barriers to recommendations. Journal of Nursing Scholarship, 48(1), 106-112.

Mills, B., Hansen, S., Nang, C., McDonald, H., Lyons-Wall, P., Hunt, J., \& O'Sullivan, T. (2020). A pilot evaluation of simulation-based interprofessional education for occupational therapy, speech pathology and dietetic students: improvements in attitudes and confidence. Journal of interprofessional care, 34(4), 472-480.

Monteiro, K., Dumenco, L., Collins, S., Bratberg, J., MacDonnell, C., Jacobson, A., ... \& George, P. (2017). An interprofessional education workshop to develop health professional student opioid misuse knowledge, attitudes, and skills. Journal of the American Pharmacists Association, 57(2), S113S117.

Muñoz-Rubilar, C. A., Carrillos, C. P., \& Díaz, C. B. (2020). Interprofessional education in nursing: The impact of collaboration between physical and mental health care professionals. International Journal of Nursing Sciences.

Olander, E., Coates, R., Brook, J., Ayers, S., \& Salmon, D. (2018). A multimethod evaluation of interprofessional education for healthcare professionals caring for women during and after pregnancy. Journal of interprofessional care, 32(4), 509-512.

Speakman, E., \& Sicks, S. (2015). Nursing in the 21st century: Find opportunities to practice in interprofessional healthcare teams. NSNA Imprint, 35-37.

Stewart, V., Crozier, M., \& Wheeler, A.

(2016). Interprofessional learning issues in postgraduate mental health education. Journal of Social Inclusion, 7(1).

Thistlethwaite, J. E. (2015).

Interprofessional education and the basic sciences: Rationale and outcomes. Anatomical sciences education, 8(4), 299-304.

Weston, C., Akinlotan, M., Lichorad, A., McClellan, D., Helduser, J., Ojinnaka, C., ... \& Bolin, J. N. (2018). The impact of interprofessional education on family nurse practitioner students' and family medicine residents' knowledge and confidence in screening for breast and cervical cancer. Journal of the American Association of Nurse Practitioners, 30(9), 511-518.

Wong, A. H. W., Gang, M., Szyld, D., \& Mahoney, H. (2016). Making an "attitude adjustment": using a simulation-enhanced interprofessional education strategy to improve attitudes toward teamwork and communication. Simulation in Healthcare, 11(2), 117125.

Zanotti, R., Sartor, G., \& Canova, C.(2015). Effectiveness of interprofessional education by on-field training for medical students, with a pre-post design. BMC medical education, 15(1), 121 